\title{
Anodic Oxide Films on Niobium and Tantalum in Different Aqueous Electrolytes and Their Impedance Characteristics
}

\author{
N. Verma ${ }^{a, *}$, K.C. Singh ${ }^{a}$, B. Marí $i^{b}$, M. Mollar ${ }^{b}$ And J. Jindal ${ }^{a}$ \\ ${ }^{a}$ Department of Chemistry, Maharshi Dayanand University, Rohtak 124001, Haryana, India \\ ${ }^{b}$ Institut de Disseny per la Fabricació Automatitzada, Departament de Física Aplicada, \\ Universitat Politècnica de València, Camí de Vera s/n, 46022 València, Spain
}

(Received November 22, 2014; revised version January 12, 2016; in final form January 20, 2016)

The anodic oxide films were prepared on the niobium and tantalum in aqueous electrolyte mixtures containing $1 \mathrm{M} \mathrm{CH}_{3} \mathrm{COOH}+1 \mathrm{M} \mathrm{H}_{3} \mathrm{PO}_{4}$ or $1 \mathrm{M} \mathrm{CH}_{3} \mathrm{COOH}+1$ vol. $\% \mathrm{HF}$ or $1 \mathrm{M} \mathrm{CH}_{3} \mathrm{COOH}+1 \mathrm{M} \mathrm{H}_{3} \mathrm{PO}_{4}+1$ vol. $\% \mathrm{HF}$ at $30 \mathrm{~V}$ for $30 \mathrm{~min}$. The barrier films were obtained on both niobium and tantalum surfaces in all electrolyte mixtures except niobium oxide film formed in $1 \mathrm{M} \mathrm{CH}_{3} \mathrm{COOH}+1$ vol. $\% \mathrm{HF}$ which is porous in nature. The anodic oxide films were characterized by FESEM. Also, electrochemical impedance spectroscopy at open-circuit potential on Nb and Ta was applied and obtained data were analyzed by fitting with four different equivalent circuits.

DOI: 10.12693/APhysPolA.129.297

PACS/topics: 68.37.Hk, 68.55.J-, 68.60.Bs

\section{Introduction}

The anodic oxide film formation on valve metals such as $\mathrm{Al}, \mathrm{Ta}, \mathrm{Nb}$, and $\mathrm{Ti}$ is an exceedingly suitable technique for producing thin oxide films. Niobium and tantalum are well known corrosion resistant materials due to spontaneous formation of anodic oxide film which is passive in nature. The passive thin film blocks the dissolution of the metal in corrosive environment [1]. The researchers have reported that stainless steel coated with niobium increases the corrosion resistance of stainless steel in $\mathrm{NaCl}$ solution [2]. The oxide film on $\mathrm{Nb}$ and $\mathrm{Ta}$ has many technological applications [3-6]. Niobium oxide has been applied in sensing materials [7-9], catalytic processes [10, 11], biocompatible films [12, 13], and in capacitor technology $[14,15]$. The use of anodic niobium and tantalum in capacitor technology is due to their high dielectric constant and reduced oxide density. The best volume-capacitance ratio is presently obtained by electrolytic capacitors based on $\mathrm{Nb}_{2} \mathrm{O}_{5}$ and $\mathrm{Ta}_{2} \mathrm{O}_{5}$ [16]. Owing to the larger permittivity of the $\mathrm{Nb}_{2} \mathrm{O}_{5}$ and more natural abundance of $\mathrm{Nb}$, the niobium oxide is considered as substitute of $\mathrm{Ta}_{2} \mathrm{O}_{5}$ in solid electrolyte tantalum $/ \mathrm{Ta}_{2} \mathrm{O}_{5}$ capacitor $[17,18]$. The porous structure on tantalum and niobium is also widely used in optical and electronic devices $[19,20]$. Niobium has been also used in piezoelectric materials [21], solar cells [22], etc. Nowadays, $\mathrm{Ta}_{2} \mathrm{O}_{5}$ and $\mathrm{Nb}_{2} \mathrm{O}_{5}$ are used as host lattices for rare-earth ion in preparation of luminescent materials [23, 24].

Anodization is well defined process to make oxide film on valve metals like $\mathrm{Ta}$ and $\mathrm{Nb}$. The formation of barrier or porous type film depends on the electrolyte composition, temperature, voltage or current density or other anodization parameters. Despite of extensive research on

*corresponding author; e-mail: vermanaveen17@gmail.com the mechanism and composition of anodic oxide film on $\mathrm{Ta}$ and $\mathrm{Nb}$ there are fewer publications on porous and non-porous oxide film on $\mathrm{Ta}$ and $\mathrm{Nb}$. A highly organized porous niobium oxide film was prepared by anodic oxidation of niobium in $\mathrm{H}_{2} \mathrm{SO}_{4}$ electrolyte with low concentrations of HF [25]. Porous structure was formed due to partial dissolution of film by reaction of oxide with $\mathrm{F}^{-}$. The porous structures were also obtained when niobium samples were anodized in $0.001 \mathrm{M} \mathrm{Na}_{2} \mathrm{SO}_{4}+0.2 \mathrm{wt} \% \mathrm{HF}$ at $5 \mathrm{~V}$. The microcones of the niobium oxide were reported, prepared by anodizing of niobium in HF electrolyte at standard temperature and pressure [26]. Amorphous niobium oxide made by dc sputtering deposition has been reported [27]. The self order niobium oxide also has been reported, prepared by electrochemical oxidation [25]. Despite of all film forming techniques discussed above and techniques like sol-gel process [28] and chemical vapor deposition [29], the anodic oxidation technique for oxide formation on metals is a less expensive method.

The chemistry and properties of anodic oxide films were highly dependent on the electrolyte used during anodization, therefore in this article we will discuss the formation of anodic oxide film on $\mathrm{Nb}$ and $\mathrm{Ta}$ in different aqueous electrolytes containing mixture of acetic acid with hydrogen fluoride or with phosphoric acid or their ternary mixture. The goal of this work was to study the morphological characteristics (porous or non-porous) of film formed in the different aqueous electrolyte mixtures and their impedance characteristics.

\section{Experimental}

Niobium and tantalum foils (99.99\% purity Sigma Aldrich) were cut in flag shaped samples for anodic oxidation. The samples were mechanically polished with emery paper up to grade 2400. Prior to the electrochemical treatment the samples were ultrasonically cleaned in acetone and ethanol followed by rinsing in deionised 
water and finally dried with hot air. Some samples were electropolished in $\mathrm{H}_{2} \mathrm{SO}_{4}+\mathrm{HF}+$ ethylene glycol mixture. The electrochemical cell consisted of a twoelectrode system in which large area $\mathrm{Pt}$ mesh was used as cathode. The voltage source and measurements of current were operated by Keithley 2400 source meter. The exposed area of the electrode was $1 \mathrm{~cm}^{2}$. The samples were anodized at constant voltage of $30 \mathrm{~V}$ at different electrolyte compositions $\left(1 \mathrm{M} \mathrm{CH}_{3} \mathrm{COOH}+1 \mathrm{M} \mathrm{H}_{3} \mathrm{PO}_{4}\right.$ or $1 \mathrm{M} \quad \mathrm{CH}_{3} \mathrm{COOH}+1$ vol. $\% \quad \mathrm{HF}$ or $1 \mathrm{M} \mathrm{CH} \mathrm{CHOH}_{3} \mathrm{CO} \mathrm{M} \mathrm{H}_{3} \mathrm{PO}_{4}+1$ vol. $\left.\% \mathrm{HF}\right)$. Measurement has been performed at room temperature $\left(30 \pm 2^{\circ} \mathrm{C}\right)$ in naturally aerated solution. After the anodization treatment the obtained samples were washed with deionized water, ethanol and dried at room temperature.

The electrochemical impedance spectroscopy (EIS) studies were done by PGSTAT (Auto lab potentiostat) at open circuit potentials with three electrode setup with $\mathrm{Ag} / \mathrm{AgCl}$ used as reference electrode. The electrolyte used was $1 \mathrm{M} \mathrm{KCl}$ solution in all impedance measurements. The module was controlled by Nova software. The frequency range of the impedance measurements was $0.1 \mathrm{~Hz}-100 \mathrm{kHz}$ at ac amplitude of $10 \mathrm{mV}$. The fitting of the data to equivalent circuits was performed using Zview software. The surface morphology of the film was investigated by FESEM Ultra 55(Zeiss Oxford Instruments).

\section{Results and discussion}

\subsection{Anodic films on niobium}

\subsubsection{Morphological analysis}

Figures 1 and 2 show the field emission scanning electron microscopy (FESEM) images of the niobium oxide film formed on niobium in different aqueous electrolyte mixtures at $30 \mathrm{~V}$ for $30 \mathrm{~min}$. The porous structures of niobium oxide were obtained after the anodic oxidation process proceeded in the aqueous electrolyte mixture of composition $1 \mathrm{M} \mathrm{CH}{ }_{3} \mathrm{COOH}+1 \mathrm{vol} . \% \mathrm{HF}$ (Fig. 1). In other electrolyte mixtures with composition $1 \mathrm{M} \mathrm{CH}_{3} \mathrm{COOH}+1 \mathrm{M} \mathrm{H}_{3} \mathrm{PO}_{4}$ or $1 \mathrm{M} \mathrm{CH}{ }_{3} \mathrm{COOH}+1 \mathrm{M} \mathrm{H}_{3} \mathrm{PO}_{4}+1$ vol. $\% \mathrm{HF}$ barrier films were formed. Previously reported works $[25,30]$ reveal that the presence of $\mathrm{F}^{-}$in the electrolyte mixture causes the dissolution of oxide film on metals like niobium and tantalum which triggers pore formation. But despite the presence of $\mathrm{F}^{-}$ion, the niobium samples anodically oxidized in $1 \mathrm{M} \mathrm{CH}{ }_{3} \mathrm{COOH}+1 \mathrm{M} \mathrm{H}_{3} \mathrm{PO}_{4}+1$ vol. $\% \mathrm{HF}$ mixtures do not show porous behavior. It means that pore formations were retarded in the presence of phosphoric acid. It may be due to the potential threshold for formation of pores shifts towards more anodic direction, caused by formation of thicker protective oxide films by phosphate or decrease in electrochemical reaction areas by $\mathrm{F}^{-}$due to competitive adsorption of $\mathrm{F}^{-}$and $\mathrm{PO}_{4}^{3-}$ on the surface of niobium [31].

Figure 1a shows the porous niobium oxide film formed on the niobium samples in $1 \mathrm{M} \mathrm{CH}_{3} \mathrm{COOH}+1$ vol. $\% \mathrm{HF}$.
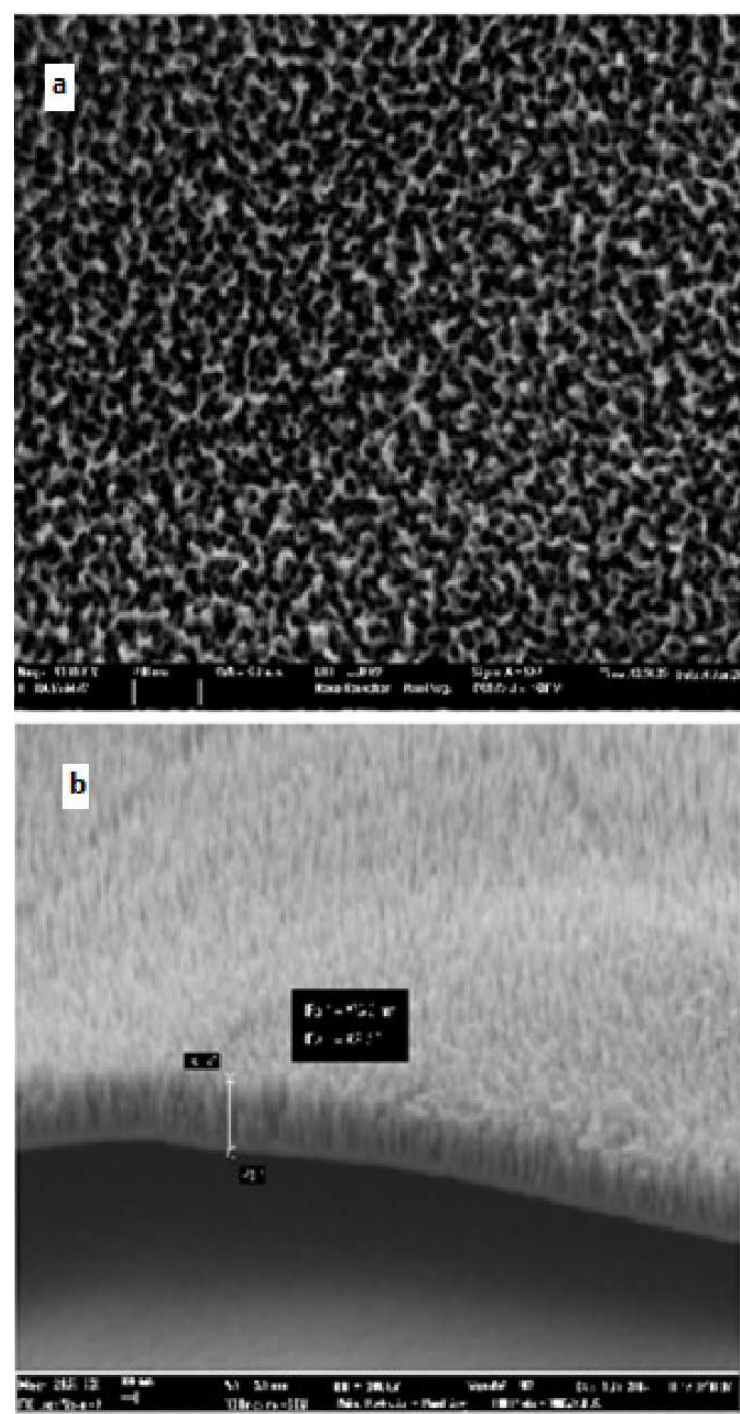

Fig. 1. FESEM images of niobium oxide in $1 \mathrm{M} \mathrm{CH}_{3} \mathrm{COOH}+1$ vol $\% \mathrm{HF}$ for 30 minutes at $30 \mathrm{~V}$ : (a) surface view (b) cross section view.

The niobium oxide film has well defined pore distribution with nanosized pores, ranging from $15 \mathrm{~nm}$ to $25 \mathrm{~nm}$. The pores were spread out on whole of the surface. The pore density found for this porous template is $2.2 \times 10^{14} \mathrm{~m}^{-2}$. For the obtaining of information about depth distribution, the FESEM cross-section was investigated for porous niobium oxide formed in $1 \mathrm{M} \mathrm{CH}_{3} \mathrm{COOH}+1 \mathrm{vol} . \% \mathrm{HF}$ at $30 \mathrm{~V}$ for 30 min shown in Fig. 1b. The FESEM cross-section images show that niobium oxide film consist of two parts, the inner part adjacent to the metallic niobium surface having thickness about 40-50 nm which is highly compact barrier film and pores were oriented vertically against the surface giving total thickness of film about $375 \mathrm{~nm}$. The aspect ratio of layer is found nearly 20. Similar behavior was observed in the reported work at $20 \mathrm{~V}$ anodization in the mixture of $1 \mathrm{M} \mathrm{H}_{2} \mathrm{SO}_{4}+1 \mathrm{wt} \% \mathrm{HF}[25]$. The formation of compact layer of $40-50 \mathrm{~nm}$ confirms the assumption 

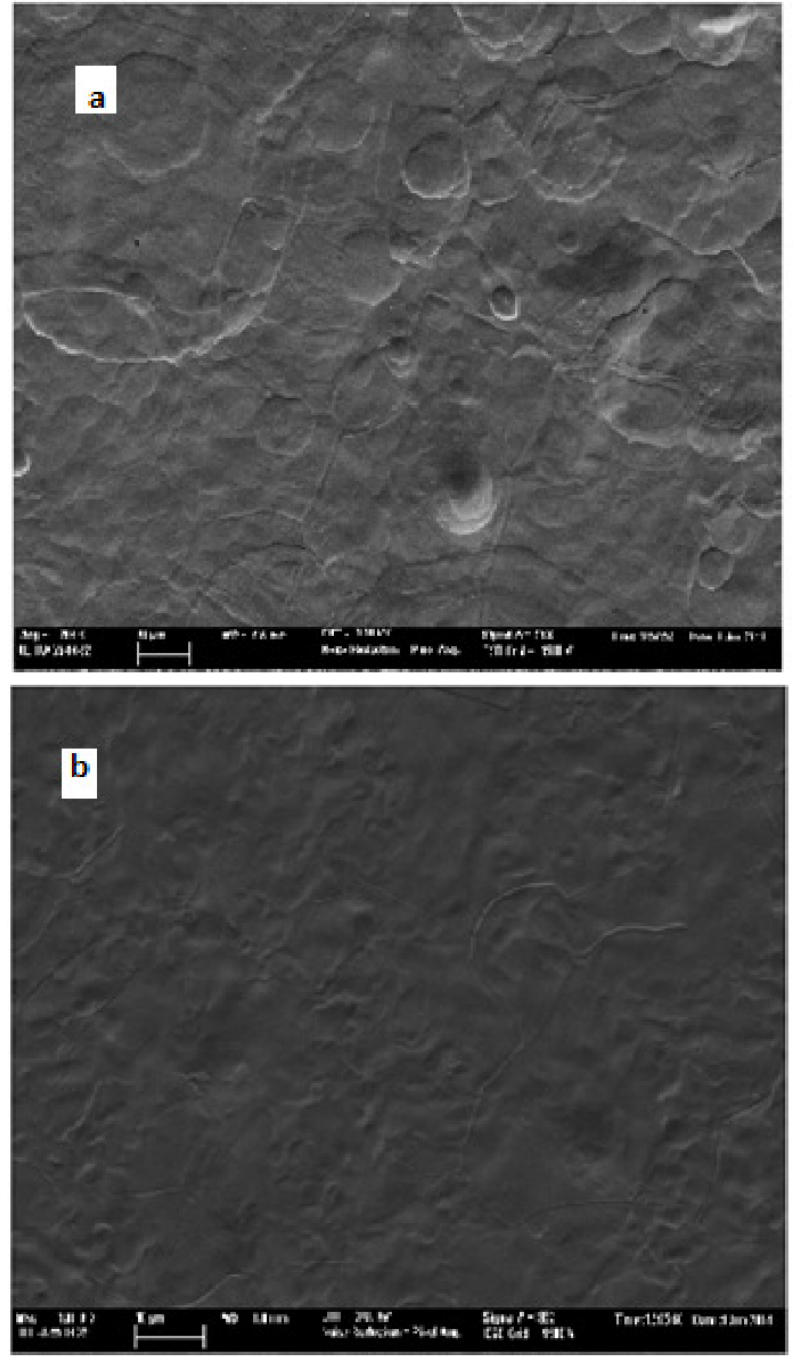

Fig. 2. FESEM images of niobium oxide film formed for 30 minutes at 30 $\mathrm{V}$ in $1 \mathrm{M} \quad \mathrm{CH}_{3} \mathrm{COOH}+1 \mathrm{M} \mathrm{H}_{3} \mathrm{PO}_{4}$ (a); $1 \mathrm{M} \mathrm{CH}{ }_{3} \mathrm{COOH}+1 \mathrm{M} \mathrm{H}_{3} \mathrm{PO}_{4}+1$ vol $\% \mathrm{HF}(\mathrm{b})$.

that pores grow in high field. The porous structure in

the cross-section shows parallel pores with homogeneous porosity.

Anodizing in different electrolyte mixtures, the oxide film shows different color. This production of color is based on the phenomenon known as optical interference of light $[32,33]$. The samples anodized in $1 \mathrm{M} \mathrm{CH} 3 \mathrm{COOH}+1 \mathrm{M} \mathrm{H} \mathrm{PO}_{4}$, $1 \mathrm{M} \quad \mathrm{CH}_{3} \mathrm{COOH}+1$ vol. $\% \mathrm{HF}$ and $1 \mathrm{M} \mathrm{CH} \mathrm{CH}_{3} \mathrm{COOH}+1 \mathrm{M} \mathrm{H}_{3} \mathrm{PO}_{4}+1$ vol. $\% \mathrm{HF}$ mixtures show light green, yellow and metallic gray in color, respectively.

\subsubsection{Impedance spectroscopy analysis}

The electrochemical impedance spectroscopy at opencircuit potential was studied on the films formed on niobium metal in aqueous electrolyte with different compositions. The impedance measurements of film formed in different electrolyte mixtures are shown in Fig. 3. The points in this figure are experimental measurements and lines are fitted curves with equivalent circuits (shown in Fig. 4). The obtained impedance experimental data for film formed in $1 \mathrm{M} \mathrm{CH}_{3} \mathrm{COOH}+1 \mathrm{M} \mathrm{H}_{3} \mathrm{PO}_{4}$ is well fitted with the Randles electrical circuit, which is one of the most common circuits. The circuit includes an uncompensated solution resistance $\left(R_{\text {sol }}\right)$, a double layer capacitor or constant phase element $(C P E)$ and a polarization resistance $\left(R_{p}\right)$. This is the starting point for other complex models. In our work we have used $C P E$ to fit the impedance of passive metal electrode. The meaning of $C P E$ is based on the oxide film showing the behavior of non-ideal capacitor. The capacitance $C_{y}$ is related to the thickness of the oxide film $d$ by Eq. (1):

$$
C_{y}=\varepsilon_{0} \varepsilon A / d,
$$

where $\varepsilon$ is the dielectric constant of film and $\varepsilon_{0}$ is the permittivity of the free space, $A$ is the surface area. Capacitance data were obtained from fitting parameters by equivalent model shown in Fig. 4a and the thickness of the film is calculated and was found as $64.6 \mathrm{~nm}$. This model is generally applied for the barrier oxide films on the metals. The evaluated impedance parameters from the fitted model are given in Table I.

TABLE I

Different parameters for niobium oxide formed from $1 \mathrm{M} \mathrm{CH} \mathrm{CH}_{3} \mathrm{COOH}+1 \mathrm{M} \mathrm{H}_{3} \mathrm{PO}_{4}$ obtained from fitting the impedance data with equivalent circuit.

\begin{tabular}{c|c|c|c}
\hline \hline electrolyte & $R_{\text {sol }}[\Omega]$ & $\mathrm{CPE}[\mathrm{F}]$ & $R_{p}[\Omega]$ \\
\hline $1 \mathrm{M} \mathrm{CH}_{3} \mathrm{COOH}+1 \mathrm{M} \mathrm{H}_{3} \mathrm{PO}_{4}$ & 3.31 & $0.57 \times 10^{-6}$ & $1.57 \times 10^{6}$
\end{tabular}

\section{TABLE II}

Different parameters for niobium oxside formed from $1 \mathrm{M} \mathrm{CH}_{3} \mathrm{COOH}+1$ vol. $\% \% \mathrm{HF}$ obtained from fitting the impedance data with equivalent circuit.

\begin{tabular}{c|c|c|c|c|c}
\hline \hline anodizing electrolyte & $R_{1}[\Omega]$ & $R_{2}[\Omega]$ & $R_{3}[\Omega]$ & $C P E_{1}[\mathrm{~F}]$ & $C P E_{2}[\mathrm{~F}]$ \\
\hline $\mathrm{CH}_{3} \mathrm{COOH}+1$ vol.\% HF & 4.9 & 52.25 & 15910 & $0.135 \times 10^{-6}$ & $0.055 \times 10^{-6}$
\end{tabular}

The film formed on niobium metal in $1 \mathrm{M} \mathrm{CH} \mathrm{CH}_{3} \mathrm{COOH}+1$ vol.\% $\mathrm{HF}$ has different types of impedance characteristics than film formed in $1 \mathrm{M} \mathrm{CH}_{3} \mathrm{COOH}+1 \mathrm{M} \mathrm{H}_{3} \mathrm{PO}_{4}$. Figure $4 \mathrm{~b}$ shows the equivalent circuit to model the anodic oxide film on niobium formed in $1 \mathrm{M} \mathrm{CH}_{3} \mathrm{COOH}+1$ vol. $\% \mathrm{HF}$. This circuit was normally used for fitting porous layer. The circuit consists of two $R C$ circuits and one resistance 

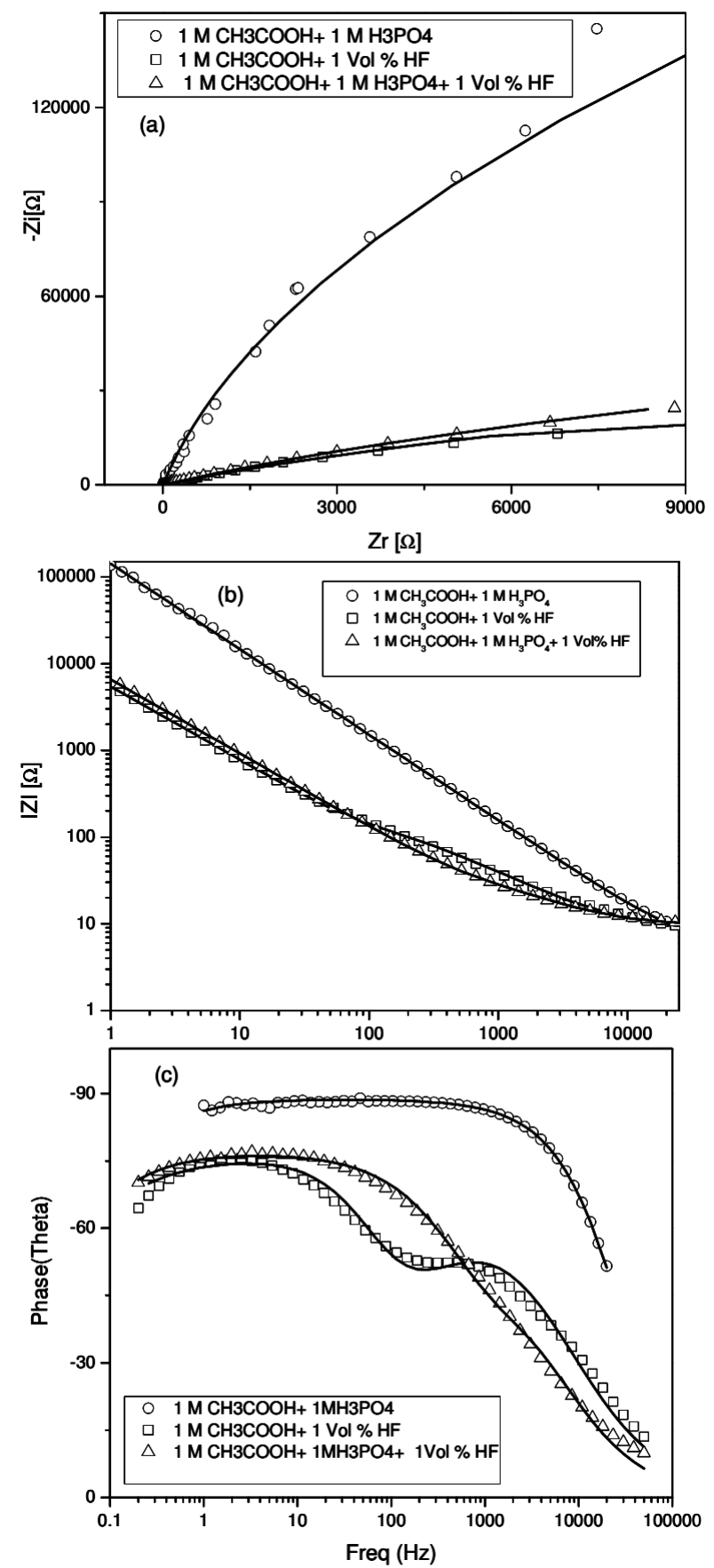

Fig. 3. Electrochemical impedance plots obtained for niobium oxide films at the open-circuit potential from all three electrolytes: Nyquist (a); Bode impedance modulus (b); Bode phase angle (c).

$R 1$; all these are connected in series. $R 3 C P E 1$ circuit corresponds to barrier layer in contact with niobium metal and $R 2 C P E 2$ with porous layer formed. The $C P E$ is frequently used instead of pure capacitance to describe interfacial dielectric properties due to presence of variation in heterogeneities in barrier and porous layer. The resistance $R_{\text {sol }}$ is the resistance associated with solution. The resistance $\mathrm{R} 2$ of the porous layer is

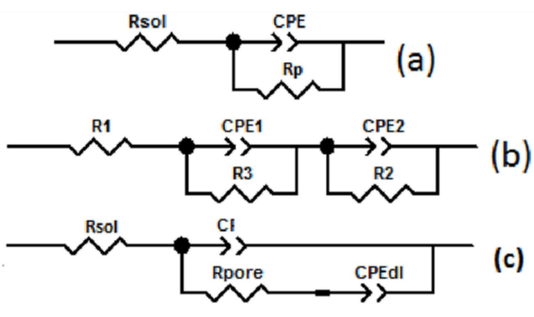

Fig. 4. Equivalent circuits fitted to experimental EIS data of anodic oxide film on niobium.
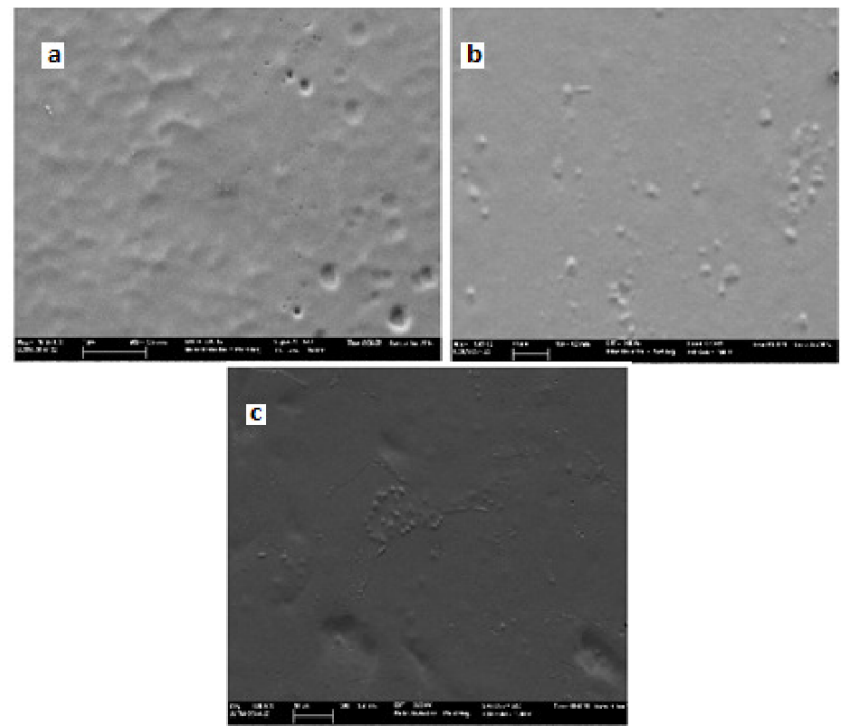

Fig. 5. FESEM images of tantalum oxide formed in $1 \mathrm{M} \mathrm{CH} 3 \mathrm{COOH}+1 \mathrm{M} \mathrm{H}_{3} \mathrm{PO}_{4}$ (a); $1 \mathrm{M} \mathrm{CH}_{3} \mathrm{COOH}+1$ vol \% $\mathrm{HF}$ (b); $1 \mathrm{M} \mathrm{CH} \mathrm{CH}_{3} \mathrm{COOH}+1 \mathrm{M} \mathrm{H}_{3} \mathrm{PO}_{4}+1$ vol\% $\mathrm{HF}$ (c) for 30 minutes at $30 \mathrm{~V}$.

very low due to ingress of the electrolyte into the pores. The incorporation of the second (R2CPE2) combination is necessary to improve the accurate estimation of EIS data. All the values obtained from modeling by this equivalent circuit are given in Table II.

The experimental impedance data were fitted with Zview software and the good agreement was observed between the experimental results and simulated curves proving that the proposed model is appropriate. The porous nature of the film is also confirmed by the FESEM image shown in Fig. 2.

The impedance characteristic of the niobium oxide film formed in $1 \mathrm{M} \mathrm{CH}_{3} \mathrm{COOH}+1 \mathrm{M} \mathrm{H}_{3} \mathrm{PO}_{4}+1$ vol. $\% \mathrm{HF}$ aqueous solution was modeled with an equivalent circuit (Fig. 4c) showing a coated substrate model where $R_{s o l}$ is the resistance solution i.e. ohmic drop across the electrolyte. This circuit has been proposed to describe the protective coatings on the metal substrates [27, 34]. In the circuit, capacitance of the perfect coating is represented by $C_{1}$ and $C P E_{d l}$ for typical double layer capacitance and ion conduction path in the film due to presence of pores or defects represented by $R_{\text {pore }}$ (equivalent circuit is shown in Fig. 4c). The percentage error was typically less than $2.5 \%$ on the $C P E$ el- 

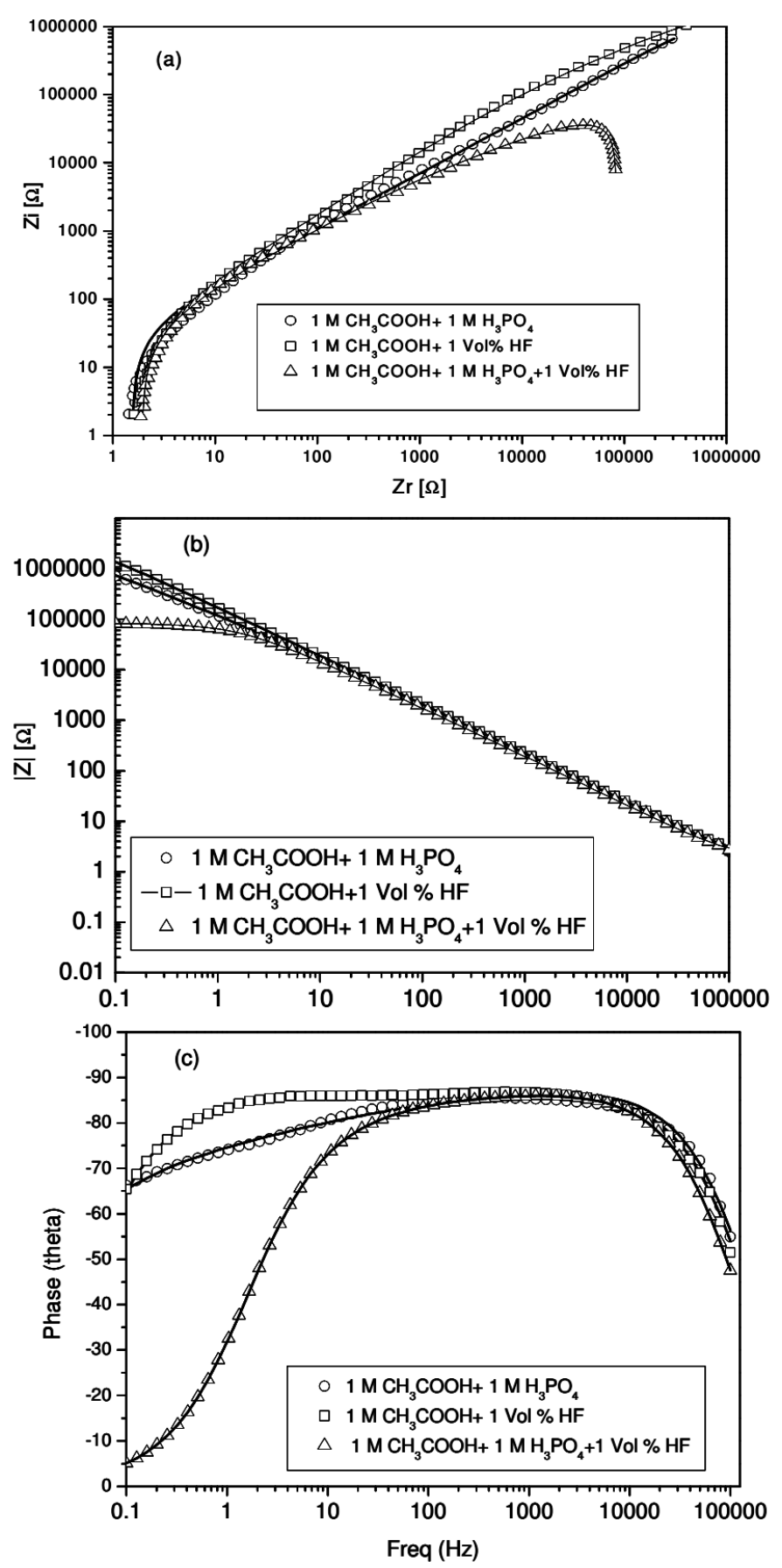

Fig. 6. Electrochemical impedance plots obtained for tantalum oxide films at the open-circuit potential from all three electrolytes: Nyquist (a); Bode impedance modulus (b); Bode phase angle (c).

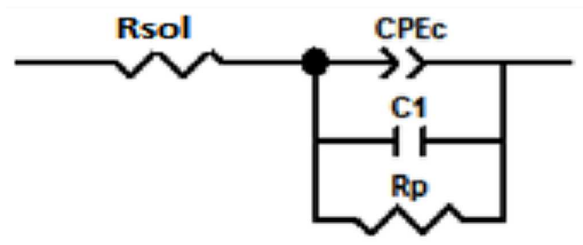

Fig. 7. Equivalent circuit fitted to experimental EIS data of anodic oxide film on tantalum. ement and 5 to $10 \%$ on other circuit elements. All the values of parameters obtained from modeling by this equivalent circuit are given in Table III. In the impedance data plots (Fig. 3a,b) it can be observed that the film formed in $1 \mathrm{M} \mathrm{CH} \mathrm{CH}_{3} \mathrm{COOH}+1 \mathrm{M} \mathrm{H}_{3} \mathrm{PO}_{4}$ shows more compact behavior than film formed in $1 \mathrm{M} \mathrm{CH}{ }_{3} \mathrm{COOH}+1 \mathrm{M} \mathrm{H}_{3} \mathrm{PO}_{4}+1$ vol. $\% \mathrm{HF}$ or $1 \mathrm{M} \mathrm{CH}_{3} \mathrm{COOH}+1$ vol.\% HF electrolyte mixture. This film has shown high impedance value and in the Bode phase plot (Fig. 3c); thus, a phase angle of $-90^{\circ}$ was observed in frequency range from $1 \mathrm{~Hz}$ to $10^{3} \mathrm{~Hz}$. The Bode plot for film formed in $1 \mathrm{M} \mathrm{CH}_{3} \mathrm{COOH}+1$ vol. $\% \mathrm{HF}$ shows that the impedance spectra consist of two time constants at low and intermediate frequency range (Fig. 3c) showing the porous nature of the film. The Bode impedance modulus plot reveals the lower magnitude of $|Z|$ in case of oxide film formed in $\mathrm{F}^{-}$containing electrolytes. This might be due to slightly more dissolution of niobium oxide in the presence of $\mathrm{F}^{-}$ions.

\subsection{Anodic oxide film on tantalum}

\subsubsection{Morphological analysis}

FESEM analysis (Fig. 5) shows that barrier type oxide films were formed on tantalum in all electrolyte compositions (as used in anodic oxidation of niobium) at $30 \mathrm{~V}$ for $30 \mathrm{~min}$. There is no pore formation even in the presence of $\mathrm{F}^{-}$in the electrolyte mixture. In the surface morphology of oxide film formed on tantalum in different aqueous electrolyte no significant difference was observed.

\subsubsection{Impedance spectroscopy analysis}

The simplest circuit which describes both Nyquist and Bode plots recorded at the open-circuit potential is composed of resistor and constant phase element/capacitor [35]. Such equivalent circuits represent the complex impedance plots (imaginary part of impedance versus real part of impedance) by straight lines. But in our experimental results of impedance measurements, curved plots instead of straight were obtained (Fig. 6a). This suggests that the equivalent circuit should be more complex. The equivalent circuit we have applied to fit the data for tantalum oxide film is shown in Fig. 7.This circuit can be derived by a more general case by omission of a capacitor due to space charge layer capacity which is much smaller than that of CPE [36, 37]. All the elements of applied circuit were found to behave in a constant manner. The series resistance $R_{\text {sol }}$ is the electrolyte resistance and comes out to be $1.4 \pm 0.5 \Omega$ in all samples. The $C P E$ is constant phase element associated with disorder either in electrode structure or in diffusion dynamics. The $C P E$ behavior may also arise due to incorporation of species in outer layer of oxide film which creates localized states in the forbidden band and induces a dispersion of the intrinsic polarization properties of the anodic oxide $[38,39]$. C1 is the space charge layer capacitance. There is good agreement between experimental data and fitted data by this equivalent circuit in whole frequency range from $10^{-1}$ to $10^{5} \mathrm{~Hz}$. High values of $\mathrm{Rp}$ are obtained, representing the resistance of 
the dielectric anodic oxide film. The magnitude of $\mathrm{Rp}$ is higher in film formed in $1 \mathrm{M} \mathrm{CH}_{3} \mathrm{COOH}+\mathrm{H}_{3} \mathrm{PO}_{4}$ mixture as compared to the same composition with presence of fluoride ion. This may be due to appearance of some flaws in the film in the presence of fluoride ions. The magnitude of $\mathrm{Rp}$ is in good agreement with the nature of the film which behaves as a wide gap semiconductor or even insulator [40]. The measured spectra show that the impedance behavior represents the passive oxide layer characteristics in which capacitive response is illustrated by phase angle above $-80^{\circ}$ over a wide frequency range. Figure $6 \mathrm{c}$ shows that there is no significant differences in the spectra of tantalum oxide film formed in $\mathrm{CH}_{3} \mathrm{COOH}+\mathrm{H}_{3} \mathrm{PO}_{4}$ and $\mathrm{CH}_{3} \mathrm{COOH}+1$ vol. $\% \mathrm{HF}$ but film formed in $\mathrm{CH}_{3} \mathrm{COOH}+\mathrm{H}_{3} \mathrm{PO}_{4}+1$ vol. $\% \mathrm{HF}$ is slightly different which shows a phase decline at lower frequencies. The film formed in $\mathrm{CH}_{3} \mathrm{COOH}+1$ vol. $\% \mathrm{HF}$ has highest value of capacitance. This may be due to some decrease in thickness caused due to etching in the presence of $\mathrm{F}^{-}$. As thickness and capacitance has reciprocate relation so these oxide films have higher capacitance. The obtained parameters by fitting equivalent circuits to the experimental data are given in Table IV.

TABLE III

Different parameters for niobium oxide formed from $1 \mathrm{M} \mathrm{CH} \mathrm{CH}_{3} \mathrm{COOH}+1 \mathrm{M} \mathrm{H}_{3} \mathrm{PO}_{4}+1$ vol.\% $\mathrm{HF}$ obtained from fitting the impedance data with equivalent circuit.

\begin{tabular}{c|c|c|c|c}
\hline \hline electrolyte composition & $R_{\text {sol }[\Omega]}$ & $C_{1}[\mathrm{~F}]$ & $C P E_{d l}[\mathrm{~F}]$ & $R_{\text {pore }}[\Omega]$ \\
\hline $1 \mathrm{M} \mathrm{CH}_{3} \mathrm{COOH}+1 \mathrm{M} \mathrm{H}_{3} \mathrm{PO}_{4}+1$ vol.\% HF & 4.98 & $1.72 \times 10^{-6}$ & $2.9 \times 10^{-5}$ & 9.39
\end{tabular}

TABLE IV

Different parameters for tantalum oxide formed from all three electrolytes obtained from fitting the impedance data with equivalent circuit.

\begin{tabular}{c|c|c|c|c}
\hline \hline electrolyte mixture & $R_{\text {sol }}[\Omega]$ & $C P E_{c}[\mathrm{~F}]$ & $C_{1}[\mathrm{~F}]$ & $R_{p}[\Omega]$ \\
\hline $1 \mathrm{M} \mathrm{CH}_{3} \mathrm{COOH}+1 \mathrm{M} \mathrm{H}_{3} \mathrm{PO}_{4}$ & 0.77 & $0.64 \times 10^{-6}$ & $3.20 \times 10^{-7}$ & $3.52 \times 10^{6}$ \\
$1 \mathrm{M} \mathrm{CH}{ }_{3} \mathrm{COOH}+1$ vol.\% HF & 0.94 & $3.25 \times 10^{-5}$ & $0.57 \times 10^{-6}$ & $3.66 \times 10^{5}$ \\
$1 \mathrm{M} \mathrm{CH}_{3} \mathrm{COOH}+1 \mathrm{M} \mathrm{H}_{3} \mathrm{PO}_{4}+1$ vol.\% HF & 0.96 & $4.90 \times 10^{-7}$ & $0.44 \times 10^{-7}$ & 42056
\end{tabular}

\section{Conclusions}

In investigations regarding the effect of electrolyte on the formation of oxide film on niobium we found that in the mixtures of $1 \mathrm{M} \mathrm{CH}_{3} \mathrm{COOH}+1 \mathrm{M} \mathrm{H}_{3} \mathrm{PO}_{4}$ or $1 \mathrm{M} \mathrm{CH} \mathrm{CH}_{3} \mathrm{COOH}+1 \mathrm{M} \mathrm{H}_{3} \mathrm{PO}_{4}+1$ vol. $\% \mathrm{HF}$ non-porous compact film was obtained but in $1 \mathrm{M} \mathrm{CH} 3 \mathrm{COOH}+1$ vol.\% $\mathrm{HF}$ mixture we have noticed the porous film having aspect ratio nearly 20 and thickness $375 \mathrm{~nm}$. It means that pore formation was retarded by phosphoric acid at the applied experimental conditions. In the case of formation of oxide film on tantalum we found that in all the electrolyte compositions i.e. $1 \mathrm{M} \mathrm{CH} \mathrm{CHOH}_{3} \mathrm{CO} \mathrm{M} \mathrm{H}_{3} \mathrm{PO}_{4}$ or $1 \mathrm{M} \mathrm{CH}{ }_{3} \mathrm{COOH}+1 \mathrm{M} \mathrm{H}_{3} \mathrm{PO}_{4}+1$ vol. $\% \mathrm{HF}$ or $1 \mathrm{M} \mathrm{CH}_{3} \mathrm{COOH}+1$ vol.\% HF mixtures the non-porous films were formed. The impedance data of the oxide films on niobium and tantalum predict the semiconductor or insulator behavior with wide band gap of the oxide film.

\section{Acknowledgments}

Naveen Verma thanks the University Grant Commission, New Delhi, India for providing final assistance under UGC major research project 40-77/2011(SR) and Jitender Jindal thanks CSIR, New Delhi, India for the award of Junior Research Fellowship.

\section{References}

[1] S. Hornkjol, Electrochim. Acta 36, 1443 (1991).

[2] J.H. Hsieh, R. Lee, R.A. Erck, G.R. Fenske, Y.Y. Su, M. Marek, R.F. Hochman, Surf. Coat. Technol. 49, 83 (1991).

[3] T. Balaji, R. Govindaiah, M.K. Sharma, Y. Purushotham, A. Kumar, T.L. Prakash, Mater. Lett. 56, 560 (2002).

[4] J.E. Yoo, J. Choi, Electrochem. Commun. 13, 298 (2011).

[5] H. Stormer, A. Weber, V. Fischer, E.I. Tiffee, D. Gerthsen, J. Eur. Ceram. Soc. 29, 1743 (2009).

[6] S.V.J. Chandra, S. Uthanna, G.M. Rao, Appl. Surf. Sci. 254, 1953 (2008).

[7] S. Rho, D. Jahng, J.H. Lim, J. Choi, J.H. Chang, S.C. Lee, K.J. Kim, Biosens. Bioelectron. 23, 852 (2008).

[8] T. Tamai, M. Haneda, T. Fujitani, H. Hamada, Catal. Commun. 8, 885 (2007).

[9] R. Binions, C.J. Carmalt, I.P. Parkin, Meas. Sci. Technol. 18, 190 (2007).

[10] T. Shishido, T. Miyatake, K. Teramura, Y. Hitomi, H. Yamashita, T. Tanaka, J. Phys. Chem. C113, 18713 (2009).

[11] A.G.S. Prado, L.B. Bolzon, C.P. Pedroso, A.O. Moura, L.L. Costa, Appl. Catal. B Environ. 82, 219 (2008). 
[12] M.T. Tanvir, Y. Aoki, H. Habazaki, Appl. Surf. Sci. 255, 8383 (2009).

[13] A. Ochsenbein, F. Chai, S. Winter, M. Traisnel, J. Breme, H.F. Hildebrand, Acta Biomater. 4, 1506 (2008).

[14] K. Cho, J. Lee, J.S. Lim, H. Lim, J. Lee, S. Park, C.Y. Yoo, S.T. Kim, U.I. Chung, J.T. Moon, Microelectron. Eng. 80, 317 (2005).

[15] J. Li, D. Yi, J. Wen, H. Zhong, H. Liu, Trans. Nonferrous Met. Soc. China 16, 848 (2006).

[16] A. Michaelis, Advanced Ceramic Oxides for Electronics, Fraunhofer IRB Verlag, Stuttgart 2006.

[17] J.S. Yoon, S.W. Cho, Y.S. Kim, B. Kim, Met. Mater. Int. 15, 405 (2009).

[18] H. Habazaki, T. Ogasawara, H. Konno, K. Shimizu, S. Nagata, K. Asami, K. Takayama, P. Skeldon, G.E. Thompson, J. Electrochem. Soc. 153, B173 (2006).

[19] R.L. Aagard, Appl. Phys. Lett. 27, 605 (1975).

[20] B. Ohtani, K. Iwai, S. Nishimoto, T. Inui, J. Electrochem. Soc. 141, 2439 (1994).

[21] X. Cheng, Q. Gou, J. Wu, X. Wang, B. Zhang, D. Xiao, J. Zhu, X. Wang, X. Lou, Ceram. Int. 40 , 5771 (2014).

[22] M. Mazur, M. Szymanska, D. Kaczmarek, M. Kalisz, D. Wojcieszak, J. Domaradzki, F. Placido, Appl. Surf. Sci. 301, 63 (2014).

[23] D.L. Zhang, P.R. Hua, Y.M. Cui, C.H. Chen, E.Y.B. Pun, J. Lumin. 127, 453 (2007).

[24] S.K. Mahesh, P.P. Rao, T.L. Francis, V.R. Reshmi, P. Koshy, Mater. Lett. 120, 115 (2014).

[25] I. Sieber, H. Hildebrand, A. Friedrich, P. Schmuki, Electrochem. Commun. 7, 97 (2005).

[26] R.L. Karlinsey, Electrochem. Commun. 7, 1190 (2005).
[27] G. Ramirez, S.E. Rodil, S. Muhl, D.T. Ortega J.J. Olaya, M. Rivera, E. Camps, L.E. Alarcon, J. Non-Cryst. Solids 356, 2714 (2010).

[28] N. Ozer, M.D. Rubin, C.M. Lampert, Solid En. Mater. Sol. Cells 40, 285 (1996).

[29] J.P. Masse, H. Szymanowski, O. Zabeida, A. Amassian, J.E.K. Sapieha, L. Martinu, Thin Solid Films 515, 1674 (2006)

[30] B. Tzvetkov, M. Bojinov, A. Girginov, J. Solid State Electrochem. 13, 1215 (2009).

[31] J. Choi, J.H. Lim, S.C. Lee, J.H. Chang, K.J. Kim, M.A. Cho, Electrochim. Acta 51, 5502 (2006).

[32] M.B.J.G. Freitas, L.O.S. Bulhoes, J. Appl. Electrochem. 27, 612 (1997).

[33] N. Magnussen, L. Quinones, D.C. Dufner, D.L. Cocke, E.A. Schweikert, B.K. Patnaik, C.V.B. Leite, G.B. Baptista, Chem. Mater. 1, 220 (1989).

[34] C. Liu, Q. Bi, A. Leyland, A. Matthews, Corros. Sci. 45, 1257 (2003)

[35] P. Pasierb, S. Komornicki, R. Gajerski, S. Kozinski, P. Tomczyk, M. Rekas, J. Electroceram. 8, 49 (2002).

[36] A. Wahl, M. Ulmann, A. Carroy, B. Jermann, M. Dolata, P. Kedzierzawski, C. Chatelain, A. Monnier, J. Augustynski, J. Electroanal. Chem. 396, 41 (1995).

[37] M. Radecka, M. Wierzbicka, M. Rekas, Physica B Condens. Matter 351, 121 (2004).

[38] Q. Lu, S. Mato, P. Skeldon, G.E. Thompson, D. Masheder, Thin Solid Films 429, 238 (2003).

[39] O. Kerrec, D. Devilliers, H. Groult, M. Chemla, Electrochim. Acta 40, 719 (1995).

[40] J.W. Schultze, V.A. Macagno, Electrochim. Acta 31, 355 (1986). 